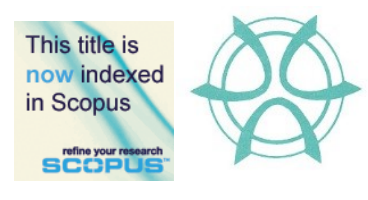

PLANNING MALAYSIA:

Journal of the Malaysian Institute of Planners

VOLUME 19 ISSUE 4 (2021), Page 244 - 256

\title{
URBAN LOW-COST HOUSING EFFECT MENTAL HEALTH
}

\author{
Nur Masyitah Ghazali ${ }^{1}$, Marlyana Azyyati Marzukhi ${ }^{2}$, Oliver Ling Hoon Leh ${ }^{3}$ \\ ${ }^{1,2,3}$ Centre of Studies for Town and Regional Planning, \\ Faculty of Architecture, Planning and Surveying, \\ UNIVERSITI TEKNOLOGI MARA, MALAYSIA
}

\begin{abstract}
As the number of people moving to urban areas increases by the year, it also increases the prevalence of mental health problems worldwide. Low-income groups in urban areas have had to choose to live in low-cost housing due to the higher cost of living. This study aims to understand the effect of living in lowcost housing. The objectives are to study and analyse mental health conditions for the low-income group living in low-cost housing in an urban area. This study was conducted at the Federal Territory of Kuala Lumpur, Malaysia. The questionnaire used is an adaptation of the Depression, Anxiety, and Stress Scale (DASS-21), and the sample selection used homogenous sampling. The site selection is based on the housing scheme's characteristics: location, density, property age, and surrounding land use. The data collected were analysed using correlation analysis to determine the relationship between urban low-cost housing living and mental health. The results have shown that 57.8 per cent of the respondents have depression, 65.7 per cent have anxiety, and 55.9 per cent have stress with various severity. The findings show that low-cost housing associated with poorer mental health is caused by several factors.
\end{abstract}

Keywords: urban environment, density, mental, health

\footnotetext{
${ }^{2}$ Lecturer at Universiti Teknologi MARA (UiTM). Email: marlyana@uitm.edu.my
} 
PLANNING MALAYSIA

Journal of the Malaysia Institute of Planners (2021)

\section{INTRODUCTION}

Mental disorders do not only affect adults but also adolescents and children. One may have mental health problems since childhood, and some due to several factors that caused them to experience mental health problems. According to the World Health Organization (WHO) (2020), almost 1 billion people are living with mental disorders and one person dies every 40 seconds by suicide. The COVID-19 pandemic impacted billions of people and worsened their mental health. The number of people with depression is 264 million, and anxiety disorders are around 284 million in 2017 worldwide (Ritchie \& Roser, 2018). Females have a higher number of mental disorders prevalence compared to males. In Southeast Asian countries, Malaysia has the highest percentage of mental disorders, and the prevalence is increasing and worsening in the COVID-19 pandemic. Mental disorders could affect anyone, and more than one disorder at a time.

In most developing countries, people with mental disorders are among the most marginalised (WHO, 2010). Socioeconomic status may cause a higher prevalence of mental disorders in urban areas, living conditions, surrounding environment, and education level. Many studies found that people born and raised in urban areas have an increased risk of mental disorders (Hoisington et al., 2019). Urban living with a higher population density is associated with a greater incidence of mental health problems (McDonald et al., 2018). As the number of people moving to urban areas is increasing by the year, the rate of mental health problems in urban areas is also increasing in line with the number of populations. Urban areas offer a limited provision of housing, land, facilities, and green spaces, which could not suffice the increasing number of populations. This study aims to understand and study the effect of low-cost urban living on mental health. The objectives are to study and analyse mental health conditions for the low-income group living in low-cost housing in urban areas, focusing on the common mental disorders of depression, anxiety, and stress.

\section{LITERATURE REVIEW}

Built environment and health has been a topic of interest for nearly half a century. Recent studies on the relationship between the built environment and health are not only on physical health but also on mental health. However, the relationship between the built environment and mental health findings is still limited and conclusive. According to Tao, Yang, and Chai (2020) and Barros et al. (2019), the built environment of a neighbourhood gives a resident an initial feeling of safety and disorder, which can be an emotional response that can improve or harm residents' social wellbeing and mental health depending on their feelings. There are abundant studies that have found that a built environment can also become a determinant affecting the risk of mental disorders. Apart from this, socioeconomic conditions and mental health of the population also have one of the characteristics in the built environment that need to be included (Amone-P'Olak et al., 2009; 
Nur Masyitah Ghazali, Marlyana Azyyati Marzukhi, Oliver Ling Hoon Leh

Urban Low-Cost Housing Effect Mental Health

Beemer et al., 2019; Garrido-Cumbrera et al., 2018; Greif \& Dodoo, 2015; Suglia et al., 2011; Xiao et al., 2018). The built environment also can, directly and indirectly, influence mental health (Evans, 2003).

\section{Low-cost housing and mental health}

Built environment consists of the physical environment and human-made features built for human use. Housing is an essential characteristic in the built environment where it is an essential requirement for shelter and people to live to work their daily life routines. In an urban area, the cost of living is higher, the land and spaces are limited, and most people could not afford medium and high-cost housing for a comfortable and better living due to their socioeconomic status limitations. Thus, the low-income group will reside in squatters or low-cost housing in the urban area, which is affordable. Housing with good housing conditions with sufficient space, higher housing quality, better housing quality, and strong housing affordability will create better mental health (Hoisington et al., 2019; Qiu et al., 2019; Wang et al., 2018). Singh et al. (2019) summarise that housing disadvantages, such as overcrowding, mortgage, delinquency, housing mobility, and housing tenure, can impact mental health.

Evans (2003) listed the direct effect of housing characteristics on mental health, such as house type, floor level, housing quality, and neighbourhood quality. Housing types, floor level, density, overcrowding and quality are associated with mental health (Marzukhi et al, 2020; Barros et al., 2019; Beemer et al., 2019; Ferguson \& Evans, 2019; Qiu et al., 2019; Shenassa et al., 2007). Li and Liu (2018) derived a conceptual framework indicating that housing can cause perceived stress and mental health problems through housing and neighbourhood stressors, the housing cost burden, overcrowding, inadequacy of indoor facilities, housing instability, and physical and social deprivation. According to Feng and Astell-Burt (2018), housing conditions such as housing types, floor, and housing facilities can directly affect mental health and indirectly affect community satisfaction, such as neighbourhood relationships, which indirectly affects mental health.

Most of the studies find a relationship between housing and mental health. This study is essential to find evidence of mental health problems in lowcost urban housing and the factors that may cause it through housing characteristics.

\section{METHODOLOGY}

This study aims to study the relationship between low-cost urban housing and mental health, and the factors contributing to it. A questionnaire was distributed to the selected area of low-cost housing in the Federal Territory of Kuala Lumpur, Malaysia, specifically at Flat Hang Tuah and Flat Sri Selangor. This study was conducted before the COVID-19 pandemic outbreak in February 2020. The sample size $(\mathrm{N}=102)$ is selected based on their availability at home and willingly participating in the survey. The sample selection uses the homogenous sampling 
method in which the respondents have similar living locations. The selected area was based on housing characteristics: density, property age, location, and surrounding land use.

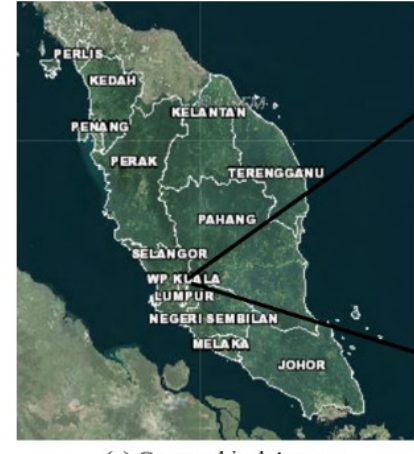

(a) Geographical Area

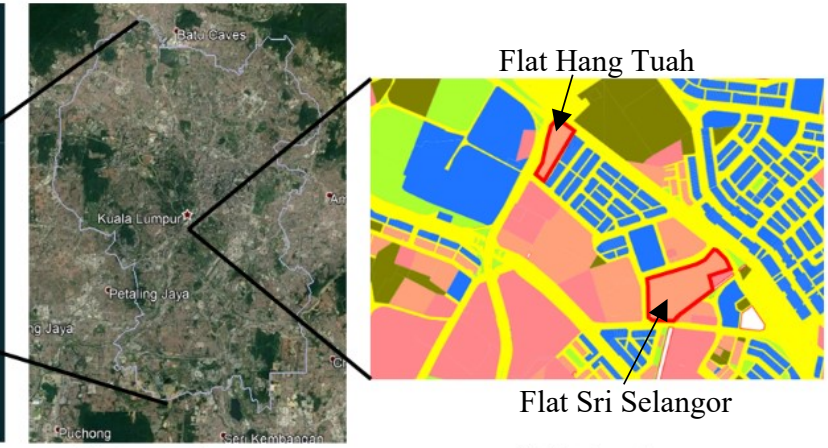

(b) Case Study Area

(c) Site Location

Figure 1: Location of Area of Interest

The questionnaire survey is divided into two sections: the respondent's demographic profile and the second section is the adaptation of the Depression, Anxiety, and Stress Scale (DASS-21). The first section consisted of the respondent's gender, age, citizenship, race, religion, academic qualification, employment status, household income, marital status, number of dependents, and homeownership status.

The second section consisted of evaluation scales adapted using the DASS-21 questionnaire, including the characteristics of the built environment and housing spaces to evaluate the factors contributing to mental health problems consisting of 23 questions. The evaluation scales responses consist of four answers: (1) "did not apply to me at all", (2) "applied to me to some degree, or some of the time", (3) "applied to me to a considerable degree or at a good part of the time", and (4) "applied to me very much or most of the time". DASS-21 questionnaire is a self-report scale designed to measure the states of depression, anxiety, and stress.

The statistical analysis is performed using the Statistical Package for Social Sciences Version 26.0 (SPSS) for the correlation analysis. The correlation analysis uses the Spearman analysis with a significance value set at $\mathrm{p}<0.05$ (onetailed) to explore the relationship between low-cost urban housing and mental health.

\section{RESULTS}

The respondents answered all the distributed questionnaires accordingly, and no questionnaire returned incomplete. The respondents who took part in the survey were male $(47.1 \%)$ and female $(52.9 \%)$. The respondents' age ranged between 15 
Nur Masyitah Ghazali, Marlyana Azyyati Marzukhi, Oliver Ling Hoon Leh

Urban Low-Cost Housing Effect Mental Health

years old and above 65 years old. Most of the respondents were between 35 and 44 years old (23.5\%). For the respondents' academic qualifications, most of them finished secondary school and are employed. The respondent's sociodemographic profile is reported in (Table 1).

Table 1: Respondent's socio-demographic profile

\begin{tabular}{lr}
\hline Variables & Percentage \\
\hline Gender & \\
Male & 47.1 \\
Female & 52.9 \\
Academic Qualification & \\
Primary School & 26.5 \\
Secondary School & 62.7 \\
Higher Education & 4.9 \\
None & 5.9 \\
Employment Status & \\
Employed & 47.1 \\
Student & 2.0 \\
Housewife & 25.5 \\
Unemployed & 25.5 \\
Household Income (MYR) & \\
Below MYR1,000 & 61.8 \\
MYR1,001 - MYR3,000 & 36.3 \\
MYR3,001 - MYR6,000 & 2.0 \\
\hline
\end{tabular}

States of depression, anxiety, and stress are analysed based on the self-reported scales of DASS-21. It is shown that 57.8 per cent of the respondents have depression, 65.7 per cent have anxiety, and 55.9 per cent have stress with various severity ranging from mild to extremely severe. More than half of the respondents have depression, anxiety, and stress from these results, and most of these people were not aware of the symptoms. Many factors may contribute to these mental health problems, and as stated in previous studies, it is shown that a built environment, such as housing, can have a direct effect on mental health (Evans, 2003).

Based on (Table 2), it is shown that depression and stress are mostly in a mild and moderate state; however, 25.5 per cent have severe and 15.7 extremely severe anxiety. According to the Mental Health Handbook (2019), anxiety refers to feeling worried, nervousness, fear, and apprehension. As the percentage of anxiety is the highest, the factors contributing to it will be analysed based on the collected data. 
PLANNING MALAYSIA

Journal of the Malaysia Institute of Planners (2021)

Table 2: Respondent's states of mental health severity

\begin{tabular}{lrrr}
\hline Severity & \multicolumn{3}{c}{ Percentage } \\
\cline { 2 - 4 } & Depression & Anxiety & \multicolumn{1}{c}{ Stress } \\
\hline Normal & 42.2 & 34.3 & 44.1 \\
Mild & 26.5 & 5.9 & 18.6 \\
Moderate & 21.6 & 18.6 & 23.5 \\
Severe & 6.9 & 25.5 & 12.7 \\
Extremely Severe & 2.9 & 15.7 & 1.0
\end{tabular}

A correlation analysis is performed involving the respondents' basic sociodemographic profile with depression, anxiety, and stress to find the relationship. The socio-demographic variables analysed were gender, age, employment status, household income, and dependents. The significant correlation of household income with anxiety is at the 0.01 level based on the analysis. The dependent's significance correlation with depression, anxiety, and stress is at the 0.01 level. The correlation analysis of the socio-demographic profile with the states of depression, anxiety, and stress is detailed in (Table 3).

Table 3: Socio-demographic and mental health relationship

\begin{tabular}{lrrr}
\hline Variables & \multicolumn{3}{c}{ Mental health states } \\
\cline { 2 - 4 } & Depression & Anxiety & \multicolumn{1}{c}{ Stress } \\
\hline Gender & -0.0 .42 & 0.125 & 0.028 \\
Coefficient (r) & 0.676 & 0.212 & 0.784 \\
Significant p Value & & & \\
Age & 0.026 & 0.013 & 0.065 \\
Coefficient (r) & 0.794 & 0.896 & 0.515 \\
Significant p Value & & & \\
Employment Status & -0.056 & 0.021 & -0.014 \\
Coefficient (r) & 0.578 & 0.834 & 0.886 \\
Significant p-Value & & & \\
Household Income & -0.090 & $-0.266^{* *}$ & -0.179 \\
Coefficient (r) & 0.369 & 0.007 & 0.072 \\
Significant p-Value & \multicolumn{3}{|}{} \\
Number of Dependants & $-0.314 * *$ & $-0.294 * *$ & $-0.324 * *$ \\
Coefficient (r) & 0.001 & 0.003 & 0.001 \\
Significant p Value &
\end{tabular}

However, based on the analysis, the relationship between gender, age, and employment status could not significantly correlate with depression, anxiety, and stress. The correlation between household income and anxiety might be due to most of the respondents' income of below MYR1,000. This income is considered a small income when living in an urban area. Most of them could not afford a better and comfortable living area. The number of dependents shows a significant correlation with depression, anxiety, and stress, which might be due to the 
Nur Masyitah Ghazali, Marlyana Azyyati Marzukhi, Oliver Ling Hoon Leh

Urban Low-Cost Housing Effect Mental Health

number of people living in one unit being overcrowded. Based on the collected data, 33.3 per cent of the respondents are residing alone or have two people in one housing unit. The remaining 66.7 per cent of respondents live together with three to ten people per housing unit. This housing scheme built up is only 650 square feet and one or two bedrooms. When the number of people living in one housing unit is more than three, this causes them to have limited space, less privacy, and inadequate spaces.

\section{Low-cost housing living effect on mental health}

Every living environment gives a different feeling to each person. The surrounding environment and in-house environment could provide a sense to the residents. A negative feeling will lead to a negative effect, especially in low-cost housing in the urban area. Most low-cost housing has smaller built-up spaces, inadequate facilities, and a noisy and deprived area. A total of ten questions were selected that consist of questions regarding the respondents' feelings toward their home and neighbourhood. The correlation analysis performed for these questions with depression, anxiety, and stress shows that neighbourhood areas and own living spaces can also affect its residents without realising it. The details of the correlation analysis are shown in (Table 4).

Table 4: Correlation between respondents feeling and mental health

\begin{tabular}{|c|c|c|c|}
\hline \multirow[t]{2}{*}{ Variables } & \multicolumn{3}{|c|}{ Mental health states } \\
\hline & Depression & Anxiety & Stress \\
\hline \multicolumn{4}{|l|}{$\begin{array}{l}\text { Negative feeling in the } \\
\text { neighbourhood area }\end{array}$} \\
\hline Coefficient (r) & $0.545 * *$ & $0.343 * *$ & $0.382 * *$ \\
\hline Significant $\mathrm{p}$ Value & 0.000 & 0.000 & 0.000 \\
\hline \multicolumn{4}{|c|}{$\begin{array}{l}\text { Sudden breathing difficulty in } \\
\text { the neighbourhood area }\end{array}$} \\
\hline Coefficient (r) & $0.287 * *$ & $0.531 * *$ & $0.457 * *$ \\
\hline Significant $\mathrm{p}$ Value & 0.003 & 0.000 & 0.000 \\
\hline \multicolumn{4}{|l|}{$\begin{array}{l}\text { Could not work up an } \\
\text { initiative at home }\end{array}$} \\
\hline Coefficient (r) & $0.606 * *$ & $0.516 * *$ & $0.629 * *$ \\
\hline Significant $\mathrm{p}$ Value & 0.000 & 0.000 & 0.000 \\
\hline \multicolumn{4}{|c|}{$\begin{array}{l}\text { Over-react to the situation at } \\
\text { home }\end{array}$} \\
\hline Coefficient (r) & $0.367 * *$ & $0.460 * *$ & $0.558 * *$ \\
\hline Significant $\mathrm{p}$ Value & 0.000 & 0.000 & 0.000 \\
\hline \multicolumn{4}{|l|}{ Agitated when at home } \\
\hline Coefficient (r) & $0.536 * *$ & $0.381 * *$ & $0.591 * *$ \\
\hline Significant $\mathrm{p}$ Value & 0.000 & 0.000 & 0.000 \\
\hline \multicolumn{4}{|c|}{ Difficulties to relax at home } \\
\hline Coefficient (r) & $0.601 * *$ & $0.401 * *$ & $0.617 * *$ \\
\hline
\end{tabular}


PLANNING MALAYSIA

Journal of the Malaysia Institute of Planners (2021)

\begin{tabular}{|c|c|c|c|}
\hline \multirow[t]{2}{*}{ Variables } & \multicolumn{3}{|c|}{$\begin{array}{c}\text { Mental health states } \\
\end{array}$} \\
\hline & Depression & Anxiety & Stress \\
\hline Significant $\mathrm{p}$ Value & 0.000 & 0.000 & 0.000 \\
\hline \multicolumn{4}{|c|}{$\begin{array}{l}\text { Feeling downhearted and blue } \\
\text { when at home }\end{array}$} \\
\hline Coefficient (r) & $0.657 * *$ & $0.333 * *$ & $0.470 * *$ \\
\hline Significant $\mathrm{p}$ Value & 0.000 & 0.001 & 0.000 \\
\hline \multicolumn{4}{|c|}{ Close to panic when at home } \\
\hline Coefficient (r) & $0.466 * *$ & $0.365 * *$ & $0.382 * *$ \\
\hline Significant $\mathrm{p}$ Value & 0.000 & 0.000 & 0.000 \\
\hline \multicolumn{4}{|c|}{$\begin{array}{l}\text { Unable to become enthusiastic } \\
\text { over anything when at home }\end{array}$} \\
\hline Coefficient (r) & $0.718 * *$ & $0.569 * *$ & $0.578 * *$ \\
\hline Significant $\mathrm{p}$ Value & 0.000 & 0.000 & 0.000 \\
\hline \multicolumn{4}{|c|}{$\begin{array}{l}\text { Feeling scared without reason } \\
\text { when at home }\end{array}$} \\
\hline Coefficient (r) & $0.445 * *$ & $0.504 * *$ & $0.362 * *$ \\
\hline Significant $\mathrm{p}$ Value & 0.000 & 0.000 & 0.000 \\
\hline
\end{tabular}

The analysis shows that the respondents' feelings when they are in their neighbourhood and home are perfectly correlated with depression, anxiety, and stress. The analysis shows that the respondents felt negative, insecure, and uneasy at home. A sense of a secure and safe neighbourhood area is vital for residents to live and perform their daily routines. However, when residents feel insecure, they will have difficulty performing their daily routine. Referring to (Table 4), the respondents' feelings are negative towards the neighbourhood and experience sudden breathing difficulties in the absence of physical exertion, which has a significant correlation at level 0.001 .

A home is the most private space and place for relaxing and resting after working for all people. However, based on the analysis, it is found that the respondents were having difficulty relaxing, feeling insecure, and could not work up with initiatives or feel enthusiastic when they are at home. This feeling has a significant correlation at level 0.0001 with depression, anxiety, and stress. All these feelings are due to the respondents not having their own private spaces and an overcrowded home. Other than that, the feeling of insecurity is due to the gloomy and dark corridors, odour, suicide cases, and criminal cases. The neighbourhood's location is near a Light Rail Transit (LRT) station and near to a hectic traffic road with high-volume commercial centres creating excessive noise that can become a contributing factor to mental health problems in the long term. This is in line with Ma et al. (2018) and Pun et al. (2019) who found that a person living near the main road has a higher possibility of having anxiety, depression, fatigue, and sleep disturbances. The summary of (Table 4) shows that the residents are not happy in their own spaces, which can lead directly and indirectly, to depression, anxiety, and stress without realising it. 
Nur Masyitah Ghazali, Marlyana Azyyati Marzukhi, Oliver Ling Hoon Leh

Urban Low-Cost Housing Effect Mental Health

\section{DISCUSSION}

The analysis shows that residents' feelings when they are in their neighbourhood area and at home can increase depression, anxiety, and stress severity. There is a strong relationship between the respondents' feelings at home and depression, anxiety, and stress. The surrounding environment and in-house spaces contribute to the feeling. Smaller units, overcrowding, noise, dark and gloomy corridors, and insecurity give the residents a long-term effect on mental health.

Previous studies found that the built environment, such as housing spaces, surrounding, in-house overcrowding, and deprived areas can affect mental health directly and indirectly (Evans, 2003; Qiu et al., 2019; Singh et al., 2019; Suglia et al., 2011; Wang et al., 2018). In-house overcrowding causes the spaces in the house to be insufficient for the dwellers and having less privacy, which affects mental health (Cable \& Sacker, 2019; Firdaus, 2017; Shultz et al., 2019; Marzukhi et al., 2020). It is in line with the significant correlation between the household number and depression, anxiety, and stress. The smaller size and limited housing units with a bigger number of households create distress for the household and are associated with mental health problems.

The location and surrounding environments, such as the surrounding land use, light, air, and provided facilities also have a relationship with mental health (Boadi et al., 2005; Kim \& Yoo, 2019; James et al., 2017). The built environment, especially housing, is associated with mental health more than physical health (Barros et al., 2019; Tao et al., 2020). The low-cost housing location is usually in a lower estate value and generally in a deprived area. In this research, the residential area is located near the Kuala Lumpur City Centre. It is a bustling place and located near one of the LRT stations, where the surrounding roads are active most of the time with the vehicle sounds. The building has also been around for more than 50 years and has low maintenance and low-quality housing.

Built environment factors are supported by socioeconomic factors associated with mental health. The household income is significantly associated with mental health (An et al., 2020; Garrido-Cumbrera et al., 2018). A long-term impact on poverty, poor housing conditions, overcrowding and mental health is found (Ma et al., 2018; Pepin et al., 2018). Most likely, the residents have a lower income and higher dependents, causing them to be in lower-income groups. Most of the respondents could not afford to live in a better residential area due to the lack of resources. Apart from that, due to these areas being a walkable distance to a commercial and public transport station, it is more economical for them to travel to work using public transport instead of using personal vehicles, which cost higher.

A person's feelings towards their daily life, their surroundings, and working up to the daily routine are essential to determine the state of their mental health well-being. The feeling can be contributed to the surrounding environment, which either creates a negative or positive feeling depending on the stressor levels. Daily routines will expose a person to a different environment (Song et al., 2018). 
PLANNING MALAYSIA

Journal of the Malaysia Institute of Planners (2021)

Shobri et al (2021) and Firdaus (2017) found that the availability of basic facilities and green spaces could improve satisfaction levels towards life, making it easier for daily routines, and make people feel better and release stress. The environment could improve mental health through vibrancy, creativity, and excitement, especially in urban high-density residential areas (Boyko \& Cooper, 2014). A negative perception or feeling threatened from the surrounding environment can contribute to poor mental health outcomes (Byers et al., 2019; Tao et al., 2020). Even though the feeling is a personal control, the surrounding environment can still affect and worsen the negative feeling if it is uncontrolled.

There were several strengths and limitations associated with low-cost living and mental health. A key strength of this study lies within the fact that the built environment, especially the housing environment, can give effect to mental health directly and indirectly, as the home is a place where people spend time the most. However, these findings are limited, as the study primarily focused on urban high-density residential and did not explore low-density residential.

\section{CONCLUSIONS}

The main conclusions of this study are drawn together and presented. These findings support the conclusion that the built environment, especially housing, is associated with mental health, whether directly or indirectly. A smaller space, an ageing building, insufficient spaces and facilities, and more environmental stressors can affect personal controls and lead to poor mental health. As the lower-income group could not afford to live in a better surrounding environment due to lack of resources, these groups often live in high-density, low-cost housing in most urban areas. As the number of dependents is increasing, and the spaces are limited, a home could not become a place where the dwellers could relax after working and the long-term effect of this has caused poor mental health that leads to mental health problems.

Housing is essential, and as a key determinant of health and happiness, the quality of life depends on the provision of housing and the facilities that come with it. Living spaces should be conducive and safe to secure people's daily life routine with minimal negativity and feeling threatened. People with mental health problems living in deprived, insecure, gloomy, dark, excessive noise, and crowded spaces will worsen their mental health problems. It will affect people with mental health problems and will gradually affect people without mental health problems in the long-term. The placement, design, facilities, and quality of low-cost housing need to be reconsidered. A low-cost housing with better lighting, ventilation, suitable location, and suitable design could improve residents' feelings about their housing quality. Thus, it affects mental health and promotes an improved quality of life. 
Nur Masyitah Ghazali, Marlyana Azyyati Marzukhi, Oliver Ling Hoon Leh

Urban Low-Cost Housing Effect Mental Health

\section{ACKNOWLEDGEMENTS}

The authors would like to express our gratitude to the Faculty of Architecture, Planning and Surveying, Universiti Teknologi MARA (UiTM), and the Ministry of Higher Education Malaysia through the Fundamental Research Grant Scheme (600-RMC/FRGS 5/3 (190/2021) for their generous contribution towards this research.

\section{REFERENCES}

Amone-P'Olak, K., Ormel, J., Huisman, M., Verhulst, F. C., Oldehinkel, A. J., \& Burger, H. (2009). Life Stressors as Mediators of the Relation Between Socioeconomic Position and Mental Health Problems in Early Adolescence: The TRAILS Study. Journal of the American Academy of Child and Adolescent Psychiatry, 48(10), 1031-1038. https://doi.org/10.1097/CHI.0b013e3181b39595

An, J., Wang, S., Cheng, M., Li, T., Sheng, L., Bian, S., ... An, J. (2020). Mental health of urban residents in the developed cities of the Yangtze River Delta in China: Measurement with the mental composite scale from the WHOQOL-BREF. Current Psychology, 39(3), 810-820. https://doi.org/10.1007/s12144-019-0142-6

Barros, P., Ng Fat, L., Garcia, L. M. T., Slovic, A. D., Thomopoulos, N., de Sá, T. H., ... Mindell, J. S. (2019). Social consequences and mental health outcomes of living in high-rise residential buildings and the influence of planning, urban design and architectural decisions: A systematic review. Cities, 93(May 2018), 263-272. https://doi.org/10.1016/j.cities.2019.05.015

Beemer, C. J., Stearns-Yoder, K. A., Schuldt, S. J., Kinney, K. A., Lowry, C. A., Postolache, T. T., ... Hoisington, A. J. (2019). A brief review on the mental health for select elements of the built environment. Indoor and Built Environment, O(0), 1-14. https://doi.org/10.1177/1420326X19889653

Boadi, K., Kuitunen, M., Raheem, K., \& Hanninen, K. (2005). Urbanisation without development: Environmental and health implications in African cities. Environment, Development and Sustainability, 7(4), 465-500. https://doi.org/10.1007/s10668004-5410-3

Boyko, C. T., \& Cooper, R. (2014). Density and Mental Wellbeing. Wellbeing, II, 1-22. https://doi.org/10.1002/9781118539415.wbwell058

Byers, K. A., Cox, S. M., Lam, R., \& Himsworth, C. G. (2019). "they're always there": Resident experiences of living with rats in a disadvantaged urban neighbourhood. BMC Public Health, 19(1), 1-13. https://doi.org/10.1186/s12889-019-7202-6

Cable, N., \& Sacker, A. (2019). Validating overcrowding measures using the UK Household Longitudinal Study. SSM - Population Health, 8(June), 100439. https://doi.org/10.1016/j.ssmph.2019.100439

Evans, G. W. (2003). The Built Environment and Mental Health. Journal of Urban Health, 80(4), 536-555. https://doi.org/10.1093/jurban/jtg063

Feng, X., \& Astell-Burt, T. (2018). Residential green space quantity and quality and symptoms of psychological distress: A 15-year longitudinal study of 3897 women in postpartum. BMC Psychiatry, 18(1), 1-11. https://doi.org/10.1186/s12888-0181926-1

Ferguson, K. T., \& Evans, G. W. (2019). The built environment and mental health. 
PLANNING MALAYSIA

Journal of the Malaysia Institute of Planners (2021)

Encyclopedia of Environmental Health, 80(December 2017), 465-469. https://doi.org/10.1016/B978-0-12-409548-9.11009-7

Firdaus, G. (2017). Built Environment and Health Outcomes: Identification of Contextual Risk Factors for Mental Well-being of Older Adults. Ageing International, 42(1), 62-77. https://doi.org/10.1007/s12126-016-9276-0

Garrido-Cumbrera, M., Gálvez Ruiz, D., Braçe, O., \& López Lara, E. (2018). Exploring the association between urban sprawl and mental health. Journal of Transport and Health, 10(June), 381-390. https://doi.org/10.1016/j.jth.2018.06.006

Greif, M. J., \& Nii-Amoo Dodoo, F. (2015). How community physical, structural, and social stressors relate to mental health in the urban slums of Accra, Ghana. Health and Place, 33, 57-66. https://doi.org/10.1016/j.healthplace.2015.02.002

Ha Kim, D., \& Yoo, S. (2019). How does the built environment in compact metropolitan cities affect health? A systematic review of korean studies. International Journal of Environmental Research and Public Health, 16(16). https://doi.org/10.3390/ijerph16162921

Hoisington, A. J., Stearns-Yoder, K. A., Schuldt, S. J., Beemer, C. J., Maestre, J. P., Kinney, K. A., ... Brenner, L. A. (2019). Ten questions concerning the built environment and mental health. Building and Environment, 155(January), 58-69. https://doi.org/10.1016/j.buildenv.2019.03.036

James, P., Hart, J. E., Banay, R. F., Laden, F., \& Signorello, L. B. (2017). Built Environment and Depression in Low-Income African Americans and Whites. American Journal of Preventive Medicine, 52(1), 74-84. https://doi.org/10.1016/j.amepre.2016.08.022

Li, J., \& Liu, Z. (2018). Housing stress and mental health of migrant populations in urban China. Cities, 81(April), 172-179. https://doi.org/10.1016/j.cities.2018.04.006

Ma, J., Li, C., Kwan, M. P., \& Chai, Y. (2018). A multilevel analysis of perceived noise pollution, geographic contexts and mental health in Beijing. International Journal of Environmental Research and Public Health, 15(7), 1-18. https://doi.org/10.3390/ijerph15071479

Marzukhi, M. A., Ghazali, N. M., Leh, O. L. H., Khalid, N. S., Kamaruddin, S. M., \& Azizul, M. F. (2020). The influence of urban planning on mental health. Case study: Federal territory of Kuala Lumpur. Planning Malaysia, 18(4), 173-190. https://doi.org/10.21837/pm.v18i14.825

McDonald, R. I., Beatley, T., \& Elmqvist, T. (2018). The green soul of the concrete jungle: the urban century, the urban psychological penalty, and the role of nature. Sustainable Earth, 1(1), 1-13. https://doi.org/10.1186/s42055-018-0002-5

Pepin, C., Muckle, G., Moisan, C., Forget-Dubois, N., \& Riva, M. (2018). Household overcrowding and psychological distress among Nunavik Inuit adolescents: a longitudinal study. International Journal of Circumpolar Health, 77(1). https://doi.org/10.1080/22423982.2018.1541395

Pun, V. C., Manjourides, J., \& Suh, H. H. (2019). Close proximity to roadway and urbanicity associated with mental ill-health in older adults. Science of the Total Environment, 658, 854-860. https://doi.org/10.1016/j.scitotenv.2018.12.221

Qiu, Y., Liu, Y., Liu, Y., \& Li, Z. (2019). Exploring the linkage between the neighborhood environment and mental health in Guangzhou, China. International Journal of Environmental Research and Public Health, 16(17). https://doi.org/10.3390/ijerph16173206 
Nur Masyitah Ghazali, Marlyana Azyyati Marzukhi, Oliver Ling Hoon Leh

Urban Low-Cost Housing Effect Mental Health

Ritchie, H., \& Roser, R. (2018). Mental Health. Retrieved from Our World in Data: https://ourworldindata.org/mental-health.

Shenassa, E. D., Daskalakis, C., Liebhaber, A., Braubach, M., \& Brown, M. J. (2007). Dampness and mold in the home and depression: An examination of mold-related illness and perceived control of one's home as possible depression pathways. American Journal of Public Health, 97(10), 1893-1899. https://doi.org/10.2105/AJPH.2006.093773

Shobri, N. I. M, Rahman, N. A., \& Saman, N. H. M. (2021). Stressed Adult's Prefrences for Outdoor Recreational Activity in Urban Parks. Planning Malaysia, 19(2), 173-185.

Shultz, J. M., Rechkemmer, A., Rai, A., \& McManus, K. T. (2019). Public Health and Mental Health Implications of Environmentally Induced Forced Migration. Disaster Medicine and Public Health Preparedness, 13(2), 116-122. https://doi.org/10.1017/dmp.2018.27

Singh, A., Daniel, L., Baker, E., \& Bentley, R. (2019). Housing Disadvantage and Poor Mental Health: A Systematic Review. American Journal of Preventive Medicine, 57(2), 262-272. https://doi.org/10.1016/j.amepre.2019.03.018

Song, Y., Huang, B., Cai, J., \& Chen, B. (2018). Dynamic assessments of population exposure to urban greenspace using multi-source big data. Science of the Total Environment, 634, 1315-1325. https://doi.org/10.1016/j.scitotenv.2018.04.061

Suglia, S. F., Duarte, C. S., \& Sandel, M. T. (2011). Housing quality, housing instability, and maternal mental health. Journal of Urban Health, 88(6), 1105-1116. https://doi.org/10.1007/s11524-011-9587-0

Tao, Y., Yang, J., \& Chai, Y. (2020). The anatomy of health-supportive neighborhoods: A multilevel analysis of built environment, perceived disorder, social interaction and mental health in Beijing. International Journal of Environmental Research and Public Health, 17(1). https://doi.org/10.3390/ijerph17010013

Wang, R., Xue, D., Liu, Y., Chen, H., \& Qiu, Y. (2018). The relationship between urbanisation and depression in China: The mediating role of neighborhood social capital. International Journal for Equity in Health, 17(1), 1-10. https://doi.org/10.1186/s12939-018-0825-x

World Health Organization. (2010, September 16). People with mental disabilities cannot be forgotten. Retrieved from World Health Organization: https://www.who.int/mediacentre/news/releases/2010/mental_disabilities_2010091 $6 / \mathrm{en} /$

World Health Organization. (2020, August 27). World Mental Health Day: an opportunity to kick-start a massive scale-up in investment in mental health. Retrieved from World Health Organization: https://www.who.int/news/item/27-08-2020-worldmental-health-day-an-opportunity-to-kick-start-a-massive-scale-up-in-investmentin-mental-health

Xiao, Y., Miao, S., Sarkar, C., Geng, H., \& Yi, L. (2018). Exploring the impacts of housing condition on migrants' mental health in nanxiang, shanghai: A structural equation modelling approach. International Journal of Environmental Research and Public Health, 15(2), 1-14. https://doi.org/10.3390/ijerph15020225 